Article

\title{
Wildfires on the Mongolian Plateau: Identifying Drivers and Spatial Distributions to Predict Wildfire Probability
}

\author{
Wu Rihan ${ }^{1,2}$, Jianjun Zhao ${ }^{1,2, *(D)}$, Hongyan Zhang ${ }^{1,2}$, Xiaoyi Guo ${ }^{1,2} \mathbb{D}^{\text {, Hong Ying }}{ }^{1,2}$, \\ Guorong Deng ${ }^{1,2}\left(\mathbb{D}\right.$ and Hui Li ${ }^{1,2}$ \\ 1 Key Laboratory of Geographical Processes and Ecological Security in Changbai Mountains, Ministry of \\ Education, School of Geographical Sciences, Northeast Normal University, Changchun 130024, China; \\ wurh651@nenu.edu.cn (W.R.); zhy@nenu.edu.cn (H.Z.); guoxy914@nenu.edu.cn (X.G.); \\ hongy864@nenu.edu.cn (H.Y.); denggr272@nenu.edu.cn (G.D.); lih795@nenu.edu.cn (H.L.) \\ 2 Urban Remote Sensing Application Innovation Center, School of Geographical Sciences, \\ Northeast Normal University, Changchun 130024, China \\ * Correspondence: zhaojj662@nenu.edu.cn; Tel.: +86-186-8651-4405
}

Received: 11 July 2019; Accepted: 11 October 2019; Published: 11 October 2019

\begin{abstract}
With climate change, significant fluctuations in wildfires have been observed on the Mongolian Plateau. The ability to predict the distribution of wildfires in the context of climate change plays a critical role in wildfire management and ecosystem maintenance. In this paper, Ripley's K function and a Random Forest (RF) model were applied to analyse the spatial patterns and main influencing factors affecting the occurrence of wildfire on the Mongolian Plateau. The results showed that the wildfires were mainly clustered in space due to the combination of influencing factors. The distance scale is less than $1 / 2$ of the length of the Mongolian Plateau; that is, it does not experience boundary effects in the study area and it meets the requirements of Ripley's K function. Among the driving factors, the fraction of vegetation coverage (FVC), land use degree (La), elevation, precipitation (pre), wet day frequency (wet), and maximum temperature $(\operatorname{tmx})$ had the greatest influences, while the aspect had the lowest influence. The likelihood of fire was mainly concentrated in the northern, eastern, and southern parts of the Mongolian Plateau and in the border area between the Inner Mongolia Autonomous Region (Inner Mongolia) and Mongolian People's Republic (Mongolia), and wildfires did not occur or occurred less frequently in the hinterland area. The fitting results of the RF model showed a prediction accuracy exceeding 90\%, which indicates that the model has a high ability to predict wildfire occurrences on the Mongolian Plateau. This study can provide a reference for predictions and decision-making related to wildfires on the Mongolian Plateau.
\end{abstract}

Keywords: driving factors; wildfire; Random Forest; Mongolian Plateau

\section{Introduction}

Wildfires are a type of natural hazard that is affected by many environmental factors and the interactions between those factors [1]. Wildfires play a macro-control role in the self-renewal and succession of ecosystems over large scale spatial and temporal ranges. The fire occurrence cycle affects changes in the geochemical cycle and the speed and stage of community succession [2]. Under global warming, the global climate has become abnormal in recent decades, and aridification has increased in the middle and high latitudes [3]. Specifically, high-temperatures, low-temperature freezing damage, uneven precipitation, continuous droughts in the spring and summer and other abnormal climatic phenomena are increasing [4]. As a result, the fire frequency and the duration of disturbances are increasing [5]. These changes affect the material cycles, energy flows, and information transmission of 
ecosystems. The spatial distribution pattern of fire occurrences has an important effect on the spatial distribution and balance of the fuel productivity, landscape characteristics, and land use patterns [6]. Moreover, fires can burn large areas within a short time, destroying the ecosystem structure and function, reducing the grade of vegetation products, dramatically changing the environment, and even threatening people's lives and property and national ecological resources [7]. Therefore, the study of the spatial distribution patterns and influencing factors of wildfires is helpful for revealing the natural causes of fire occurrences and their impacts on various ecological processes.

A common approach when analysing the influencing factors of wildfires is the use of a traditional method that can be used to predict wildfire occurrences with respect to different variables. The traditional method is powerful in terms of its prediction power, but it is limited by the assumptions of normality and linear relationships [8]. In recent years, the Random Forest (RF) model has been widely applied in the field of ecology and exhibits a high prediction accuracy [9]. A few scholars have applied RF models to forest fire prediction, and those models have shown good predictive power [10]. Compared with traditional methods, machine learning algorithms can overcome subjective factors and are widely used in various research fields [11]. The commonly used machine learning algorithms include artificial neural networks, support vector machines and classification and regression trees. However, the above machine learning methods also have some shortcomings. Artificial neural networks have the disadvantages of difficulty in determining the initial weights and a slow convergence speed. Classification and regression trees are sensitive to data noise and training sample errors. How the selection of the kernel functions of support vector machines affects the classification accuracy remains uncertain [12]. These shortcomings affect the accuracies of the researches results. By contrast, RF is a non-parametric machine learning ensemble algorithm that has a strong anti-noise ability and low sensitivity to outliers and can effectively overcome the over fitting phenomenon [13]. Based on these advantages, RF has achieved high classification accuracy in research, and it is gradually becoming widely used in the remote sensing image classification field [14].

The Mongolian Plateau is the main region of temperate grassland in Eurasia and is an area where fires are extremely active [15]. Some research results in this area show that the fire occurrence in parts of the Mongolian Plateau is dominated by climatic factors such as precipitation, humidity, temperature and wind speed [16]. In the context of global warming, wildfire prevention is facing a severe challenge $[17,18]$. The occurrence of a single wildfire may be regarded as a random event, but the occurrence and distribution of wildfires on the landscape and even at the regional scale are not completely random; rather, they present certain spatial and temporal distribution characteristics [19]. Traditional wildfire occurrence information is mainly derived from statistical data; it is difficult to cover large areas because data collection is difficult, and quantifying the data space is challenging. Around the year 2000, the rapid development of remote sensing technology began to greatly improve the accuracy of large-scale and sudden wildfire monitoring. Burned area data are widely available in near-real time by remote sensing. We select the Moderate Resolution Imaging Spectroradiometer (MODIS) burned area product MCD64A1 data to study wildfires on the Mongolian Plateau and accomplish the following objectives: (1) identify the spatial distribution of wildfires on the Mongolian Plateau, (2) understand the comprehensive influencing factors affecting fire occurrence, and (3) produce spatially explicit statistical models and a map predicting patterns of wildfires on the Mongolian Plateau based on various driving factors.

\section{Materials and Methods}

\subsection{Study Area}

The Mongolian Plateau is located in the central part of Eurasia, and it includes all of Mongolia, southern Siberia in Russia and northern China [15]. This paper selects the main part of the Central Mongolian Plateau (the scope is $\left.87^{\circ}-126^{\circ} 04^{\prime} \mathrm{E}, 37^{\circ} 22^{\prime}-53^{\circ} 20^{\prime} \mathrm{N}\right)$, i.e., the Inner Mongolia Autonomous Region (Inner Mongolia) and Mongolian People's Republic (Mongolia) as the research area (Figure 1); 
The total area of the whole region is $2.74 \times 10^{6} \mathrm{~km}^{2}$ [20]. The study area has a temperate continental climate, experiencing low and uneven precipitation. The winter is long and cold, with an average monthly winter temperature of $-10{ }^{\circ} \mathrm{C}$ in the south to $-38^{\circ} \mathrm{C}$ in the north. The summer is warm and short, and the average monthly summer temperature ranges from 16 to $27^{\circ} \mathrm{C}$. Influenced by the topography and oceanic weather system, the precipitation ranges from $50 \mathrm{~mm}$ in the west to $700 \mathrm{~mm}$ in the east.

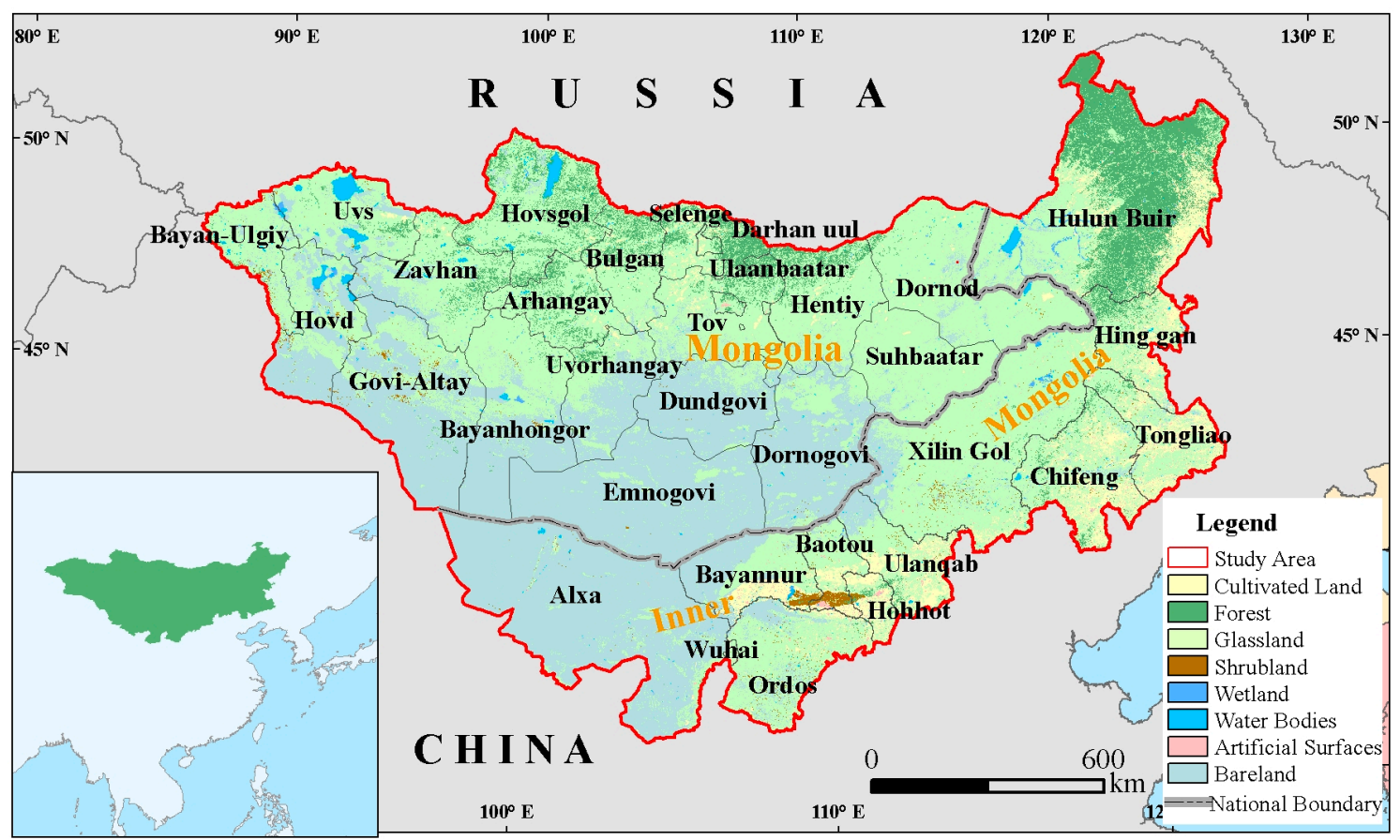

Figure 1. The location of the Mongolian Plateau and land cover.

\subsection{Data and Variables Selected}

\subsubsection{Wildfire Data}

The burned area product MCD64A1 used in this study is derived from MODIS. The MCD64A1 is a monthly Level 3 gridded $500 \mathrm{~m}$ product. The original data from MCD64A1 includes 5 types of information comprising the burn date, burn date uncertainty, quality assessment, first day, and last day [21-23]. We used the burn date layer data; the detailed classification information is shown in Table 1. Data on wildfires on the Mongolian Plateau from 2001 to 2018 were included. When the RF was established, $75 \%$ of the data were used as training data, and $25 \%$ were used as test data.

Table 1. MCD64A1 fire mask pixel classes.

\begin{tabular}{cc}
\hline Class & Meaning \\
\hline-2 & Water \\
-1 & Unmapped due to insufficient data \\
0 & Unburned land \\
$1-366$ & Ordinal day of burn \\
\hline
\end{tabular}

\subsubsection{Land Cover Data}

The MODIS land cover product (MCD12Q1) defines 17 types of land cover based on the International Geosphere-Biosphere Program (IGBP) global vegetation classification. This article uses the dataset to complete the following two tasks. First, we used MCD12Q1 to calculate the land use degree (LA), indicating the impact of human activities on wildfire [24]. The LA mainly reflects the 
land use condition. In addition, the LA reflects the degree of human utilization of land to a certain extent. In this paper, a quantitative comprehensive weight index was selected to explain the land use degree in various ecosystem. Second, the data were used to remove urban land, rural residential land, snow, and water bodies from the wildfire analysis. The meaning of each class is shown in Table 2.

Table 2. Land cover types of the Mongolian Plateau extracted from MCD12Q1.

\begin{tabular}{cccc}
\hline Class & Meaning & Class & Meaning \\
\hline 1 & Evergreen Needleleaf Forest & 10 & Grassland \\
3 & Deciduous Needleleaf Forest & 11 & Permanent Wetlands \\
4 & Deciduous Broadleaf Forest & 12 & Croplands \\
5 & Mixed Forest & 13 & Urban Land, Rural Residential Land \\
7 & Open Shrublands & 14 & Cropland/Natural Vegetation Mosaic \\
8 & Woody Savannas & 15 & Snow, Water \\
9 & Savannas & 16 & Barren \\
\hline
\end{tabular}

\subsubsection{Climate Data}

Climatic Research Unit (CRU) grid data based on monthly observations at meteorological stations across the world's land areas were used in combination with existing climatology to obtain absolute monthly values [25]. The dataset includes climate variables such as the diurnal temperature range (dtr), frost day frequency (frs), potential evapotranspiration (pet), precipitation (pre), daily mean temperature (tmp), monthly average daily minimum/maximum temperature (tmn/tmx), relative humidity (rhm), sunshine duration (ssh), vapor pressure (vap), wet day frequency (wet) and wind speed (wnd). In this paper, the CRU4.01 dataset variables are selected, the time coverage is the years 2000-2016, and the spatial resolution is $0.5^{\circ} \times 0.5^{\circ}$.

\subsubsection{Vegetation Cover}

The fraction of vegetation coverage (FVC) is usually defined as the percentage of the vertical projected area of vegetation (including leaves, stems, and branches) on the ground as a percentage of the total area [26]. The FVC is an important parameter not only for describing vegetation cover but also for reflecting vegetation growth on the ground [27]. It is also the most important and sensitive index for monitoring grassland degradation. In this paper, we use the pixel binary model to invert the vegetation coverage. The calculation formula is as follows:

$$
\mathrm{FVC}=\left(\mathrm{NDVI}-\mathrm{NDVI}_{\mathrm{soil}}\right) /\left(\mathrm{NDVI}_{\mathrm{veg}}-\mathrm{NDVI}_{\mathrm{soil}}\right)
$$

where $\mathrm{NDVI}_{\text {soil }}$ is the pixel value of bare soil or vegetation free areas and $\mathrm{NDVI}_{\mathrm{veg}}$ is the pixel value of pure vegetation. For most types of bare soil surfaces, the theoretical $\mathrm{NDVI}_{\text {soil }}$ value should be close to 0 . Because of differences in the atmospheric influence and surface temperature, humidity, roughness and soil type, its value will change over time and space. In this paper, we chose empirical values of $\mathrm{NDVI}_{\mathrm{veg}}=0.70$ and $\mathrm{NDVI}_{\text {soil }}=0.05$, that is, when the NDVI pixel value was greater than 0.70 , the FVC value was 1 ; and when the NDVI value was less than 0.05 , the FVC value was 0 [26].

\subsubsection{Topography}

The elevation spatial resolution is $90 \mathrm{~m}$. The influence of the terrain on the occurrence of wildfire is expressed by calculating the elevation, slope and aspect information of the study area. Details of the driving factors are presented in Table 3. 
Table 3. Predictor variables included in wildfire model development for the study area.

\begin{tabular}{cccc}
\hline Variable Type & Variable Name & Code & Source \\
\hline Wildfire & wildfire & wildfire & https://ladsweb.eosdis.nasa.gov/ \\
Land cover & land use degree & LA & https://earthdata.nasa.gov \\
& diurnal temperature range & $\mathrm{dtr}$ & https://crudata.uea.ac.uk/cru/ \\
& frost day frequency & frs & \\
potential evapotranspiration & pet & \\
plimatic & precipitation & pre & \\
& daily mean temperature & tmp & \\
& monthly average minimum temperature & tmn & \\
& monthly average maximum temperature & tmx & \\
Vegetation & vapor pressure & vap & \\
& wet day frequency & wet & https://earthdata.nasa.gov \\
Topographic & fraction of vegetation coverage & FVC & http://www.gscloud.cn \\
& elevation & elevation & \\
& slope & slope & \\
\hline
\end{tabular}

\subsection{Methods}

\subsubsection{Spatial Distribution Analysis}

Ripley's K function has become one of the most effective methods for studying the spatial distribution pattern of point features. In this study, Ripley's K function was used to analyse the spatial aggregation characteristics of wildfires on the Mongolian Plateau using ArcGIS. When applying Ripley's $\mathrm{K}$ function, it is assumed that the fire points in the study area have an even spatial distribution [28]. In addition, the application variable $k(d)$ expresses the ratio between the average number of sample fire points in the range of distance $d$ and the sample fire point density in the study area:

$$
\mathrm{k}(\mathrm{d})=\mathrm{A} \sum_{\mathrm{i}=1}^{\mathrm{n}} \sum_{\mathrm{j}=1}^{\mathrm{n}} \frac{\mathrm{w}_{\mathrm{ij}}}{\mathrm{n}^{2}}
$$

where $\mathrm{n}$ is the total number of fire points; $\mathrm{w}$ is defined as the distance, which is the distance between all fire points $i$ and fire point $j$ in the range of $d$ distance; and $A$ is the area of the study area.

Ripley's K function determines whether the spatial pattern of the actual observed fire points is agglomerated, divergent, or evenly distributed depending on the index $\mathrm{L}(\mathrm{d})$ and $\Delta(\mathrm{d})$ :

$$
\mathrm{L}(\mathrm{d})=\sqrt{\frac{\Delta(\mathrm{d})}{\mathrm{n}}}
$$

when $\mathrm{L}(\mathrm{d})<\Delta(\mathrm{d})$, the spatial distribution pattern of the fire points appears as a diffuse distribution; when it is larger than $\Delta(\mathrm{d})$, it appears as an aggregated distribution.

\subsubsection{Land Use Degree}

The LA reflects the degree of land development. The driving factors behind land use and land cover change mainly derive from human activities. Therefore, the quantitative LA can more clearly indicate the impact of human activities [29]. When calculating the LA, croplands are classified as cultivated land; barren is classified as unused land; and urban land and rural residential land are classified as artificial surfaces. The detailed classification information is shown in Table 4 . To explore the influence of land use on wildfires, this paper introduces the land use degree index LA. The specific formula is as follows:

$$
\mathrm{LA}=100 \times \sum_{\mathrm{i}=1}^{\mathrm{n}}\left(\mathrm{A}_{\mathrm{i}} \times \mathrm{C}_{\mathrm{i}}\right) \mathrm{LA} \in(100,400)
$$

where $A_{i}$ is the $i$ type land use level index, $C_{i}$ is the percentage of land use at the $i$ level in the study area, and $\mathrm{n}$ is the number of land use classifications. According to the above criteria of land use indicators, 
the allocation table of land use classification indicators in the study area was obtained. Table 4 shows the classification index for land use.

Table 4. Classification index of land use.

\begin{tabular}{ccc}
\hline Classifications of LA & Land Use/Land Cover & Classification \\
\hline Unused land & Barren & 1 \\
Grassland forest and water & Forest/grassland/water & 2 \\
Cultivated land & Croplands & 3 \\
Artificial surface & Urban land, rural residential land & 4 \\
\hline
\end{tabular}

\subsubsection{RF Model}

The RF model improves the prediction accuracy of the model by aggregating a large number of classification regression trees, which can be used to solve classification and regression problems [30]. The sample dataset of each tree is generated by bootstrap resampling technology. The out-of-bag (OOB) method is used to test the goodness of fit of the model [31]. The bootstrap resampling technique is used to extract $\mathrm{k}$ sample datasets from the original dataset. The sample size of each sample dataset is the same as that of the original dataset. Then, $\mathrm{k}$ classification trees are established for the $\mathrm{k}$ sample datasets, and k classification results are obtained; finally, the final RF classification results are obtained by voting on the $\mathrm{k}$ classification results separately.

Assuming that the original data contain $m$ variables, a number of random variables are randomly selected at each node of each classification tree. When applying the RF to data fitting and prediction, it is necessary to parameterize the number of trees (ntree), the $m$ try $(m t r y<m$ ) of each partitioning node and the minimum number of observations (nodesize) on the final node, in which mtry and ntree are the two most important custom parameters. When $m$ try $=m$ is a better choice [32]. As long as the value of ntree is large enough, the total error rate of the model tends toward a stable upper bound to ensure the convergence of the RF. Therefore, this paper sets the value of $m$ try to $m$ and that of $n$ tree to 3000 .

This paper uses RStudio to run the RF model. RF takes the minimum out-of-bag error (errOOB) as the principle by which to select the feature variables of the model and ranks the feature variables with the importance score. The specific methods are as follows. For the variable $X_{i}$, the errOOB ${ }_{t}$ of each tree $t$ is calculated, and then, when the sequences of all other variables remains unchanged, the sequence order of the $X_{i}$ values of the variables in the errOOB data is changed, and the errOOB ${ }_{t}^{\prime}$ of errOOB is recalculated. Finally, the increase in errOOB is calculated when the errOOB data sequence changes. The formula for calculating the importance score of variable $X_{i}$ is:

$$
\mathrm{VI}\left(\mathrm{X}_{\mathrm{i}}\right)=\frac{1}{\text { ntree }} \sum\left(\operatorname{errOOB}_{\mathrm{t}}^{\prime}-\operatorname{errOOB}_{\mathrm{t}}\right)
$$

\subsubsection{Test RF Model}

The receiver operating characteristic (ROC) curve can be used to verify the accuracy of the RF results [2]. The ROC curve calculates a series of sensitivity and specificity values by setting several different critical values for continuous variables. The sensitivity is then used as an ordinate and the specificity as an abscissa to draw curves. The area under the curve (AUC) is an evaluation index used to evaluate the accuracy of the model prediction. As the AUC becomes larger, the model has a better fitting effect. An AUC of 0.5-0.7 indicates a poor fit, 0.7-0.9 indicates a moderate fit, and above 0.9 indicates a very good fit of the model [33].

The Yueden index was used to estimate the cut-off point, which is the threshold for the determination of the prediction accuracy of the RF [34]. It is calculated based on the sensitivity and specificity of the ROC. If the predicted likelihood of the model is larger than the cut-off point, a wildfire has occurred. Otherwise, the case is registered as having no wildfire. 


\subsubsection{Mapping the Probability of Wildfire Occurrences}

Finally, a map of the wildfire occurrence probability was obtained using RStudio based on the RF model using the full dataset.

\section{Results}

\subsection{Spatial Pattern of Wildfires on the Mongolian Plateau}

Figure 2 shows the spatial distribution of wildfires in the fire risk period (April, May, June, September, October, and the full fire risk period). The theoretical value is lower than the observed value within $1150 \mathrm{~km}$. The result indicates that the wildfires are aggregated within $1150 \mathrm{~km}$. Otherwise, the wildfires are not clustered. The statistical result shows that the observed value is greater than the upper limit of the $99 \%$ confidence level, and thus the aggregation distribution is significant. The distribution of wildfires in the fire risk period is an aggregated distribution within $1150 \mathrm{~km}$. From the distance of aggregation, the aggregation intensity in May is the largest, followed by those in June, September and October, and the smallest is in April.

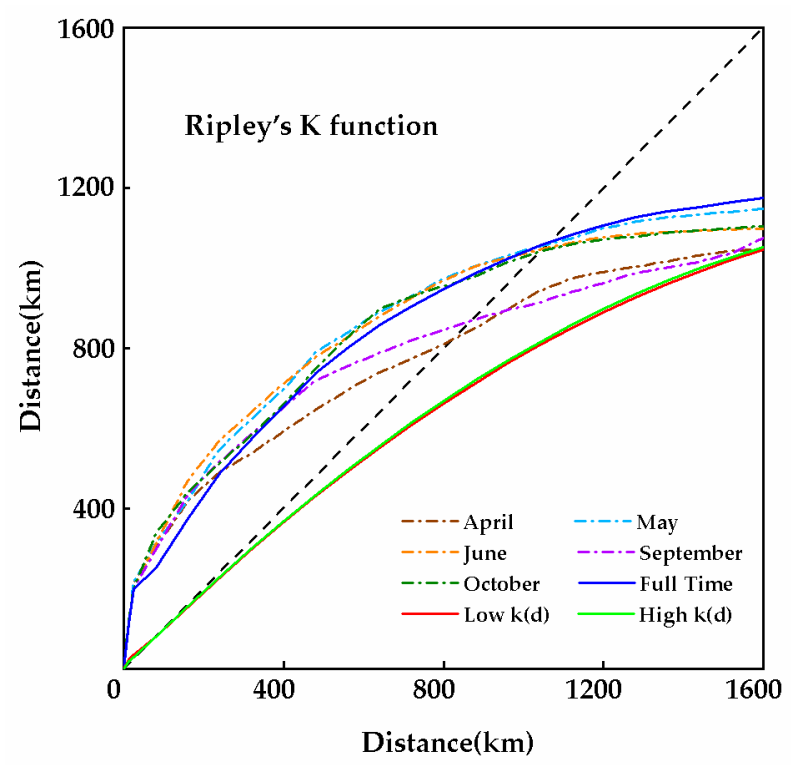

Figure 2. Spatial distribution of wildfire on the Mongolian Plateau.

\subsection{Selection and Ranking of Characteristic Variables}

$\mathrm{RF}$ is an ensemble learning technique consisting of a combination of many classification trees, where each tree is generated by bootstrap samples in this study. The original wildfire data (2001-2018) were randomly divided into training $(75 \%)$ and validation (25\%) samples. Different sets of samples from the dataset are obtained by repeated partitioning five times. In this paper, after using the RF model to select the model variables from the three training sample datasets and the full sample dataset, the importance of the fire impact factors is ranked according to the mean decrease accuracy value. The variable ranking results (Figure 3) for the whole fire risk period indicated that the fraction of vegetation coverage (FVC), land use degree (LA), elevation, precipitation (pre), wet day frequency (wet), and maximum temperature (tmx) accounted for the greatest contributions among the factors affecting the wildfire occurrence on the Mongolian Plateau, while the aspect accounted for the lowest contribution. The contribution rates of the diurnal temperature range (dtr), slope, vapour pressure (vap), minimum temperature (tmn), potential evapotranspiration (pet), and frost day frequency (frs) were similar and presented small differences. 
(a) Sample 1

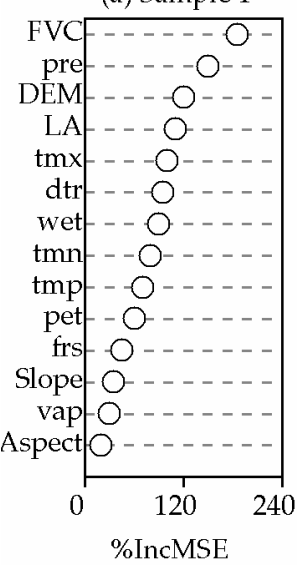

(b) Sample 2

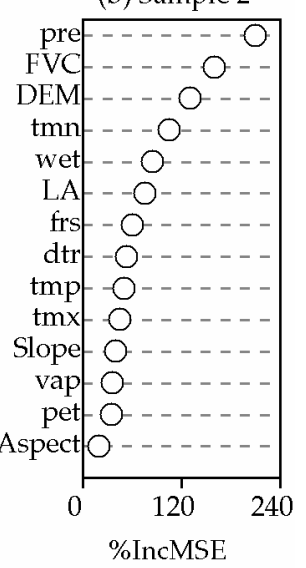

(C) Sample 3

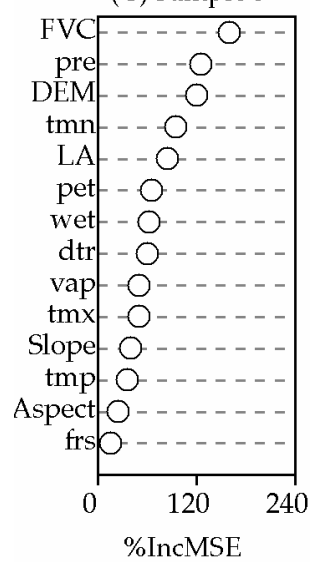

(d) Fire Risk Period

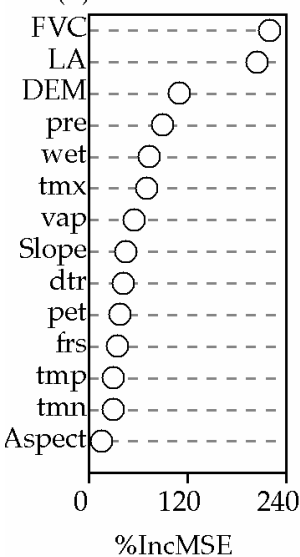

Figure 3. Variable importance measures from RF sub-samples $(\mathbf{a}-\mathbf{c})$ and complete dataset (d) based on mean decrease accuracy (\%IncMSE), which quantifies the importance of a variable by measuring the change in the prediction accuracy when the values of the variable are randomly permuted compared with the original observations. The abbreviated variable names are the same as in Table 3.

\subsection{Test RF Model}

The ROC curve analysis method was used to test the fitting superiority of the RF model. Table 5 shows the ROC curves of the complete dataset and the three samples. It can be seen from the table that the AUC values of the whole dataset and the three sample wildfires are all between $(0.9,1]$. The RF model thus fits all samples very well, and the significance level of all samples is less than 0.001 . Thus, it has statistical significance. The result shows that the RF model can be applied for the prediction of wildfires on the Mongolian Plateau.

Table 5. AUC and significance level of the RF model.

\begin{tabular}{ccccc}
\hline & Complete Dataset & Sample 1 & Sample 2 & Sample 3 \\
\hline AUC & 0.951 & 0.948 & 0.950 & 0.949 \\
$p$-value & $<0.001$ & $<0.001$ & $<0.001$ & $<0.001$ \\
\hline
\end{tabular}

\subsection{Spatial Distribution of Wildfire Probability}

In this paper, $75 \%$ of the wildfire data (2001-2018) were used as training data for the RF model to obtain the fire likelihood distribution. The distribution of the wildfire likelihood on the Mongolian Plateau (Figure 4) shows that wildfires in the study area are not randomly distributed and follow certain spatial distribution rules. There are more wildfires in the northern, eastern and southern parts of the Mongolian Plateau and in the border area between Inner Mongolia and Mongolia, and wildfires do not occur or occur with less frequency in the hinterland area. The wildfire risk zones on the Mongolian mostly occur in the east and north but seldom occur in the south and west. There are four main areas in multiple zones: the meadow grassland at the junction of the eastern part and Inner Mongolia, a forest-grassland transition zone in the northern part, a grassland in the southern part, and a typical grassland in the central part of Suhbaatar province. Wildfires occur less frequently in the transition zone between the typical grassland and the desert grassland in the western part. In Inner Mongolia, the wildfire risk zone shows a striped pattern from the northeast to southwest. The fire occurrence zone mainly includes the following areas: Hulun Buir, Tongliao, Hing gan League, the junction of Chifeng city and the Xilin Gol League, and the Ordos Grassland. 

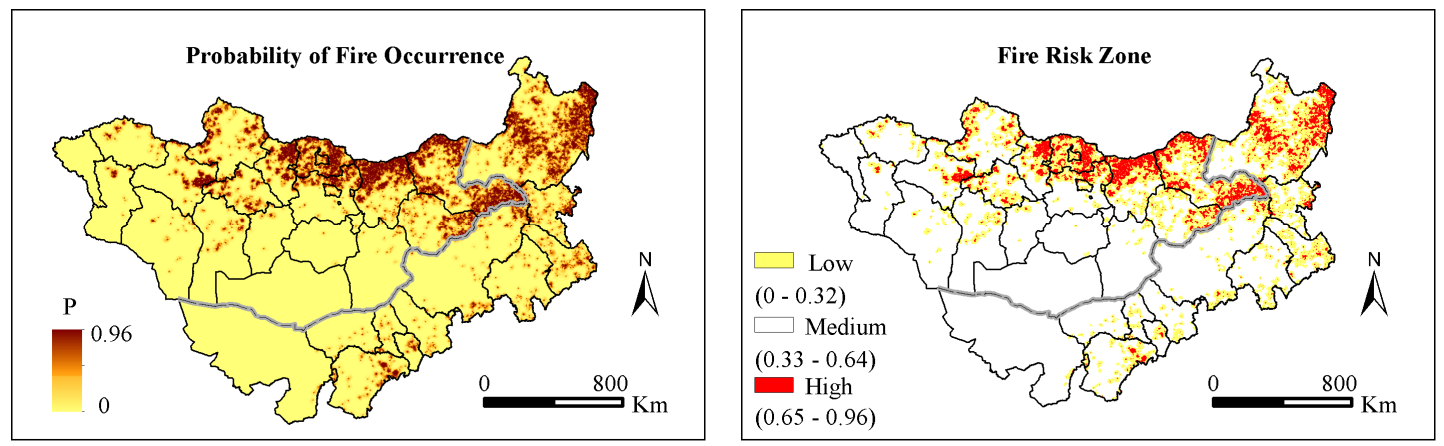

Figure 4. Probability of fire occurrence and fire risk zone on the Mongolian Plateau.

\subsection{Spatial Distribution of Residual in RF Model}

We also conducted residual analysis (wildfire (0/1)-wildfire probability) based on the full dataset. Figure 5 indicates that the RF model had the best fit (i.e., smaller residuals across the Mongolian Plateau). The positive (under prediction) and negative (over prediction) residuals of the RF model were smaller residuals across the Mongolian Plateau. The under predictions were mainly located in the middle and southern part of the study area, while the over predictions were located in the northern and northeastern part of the Mongolian Plateau.

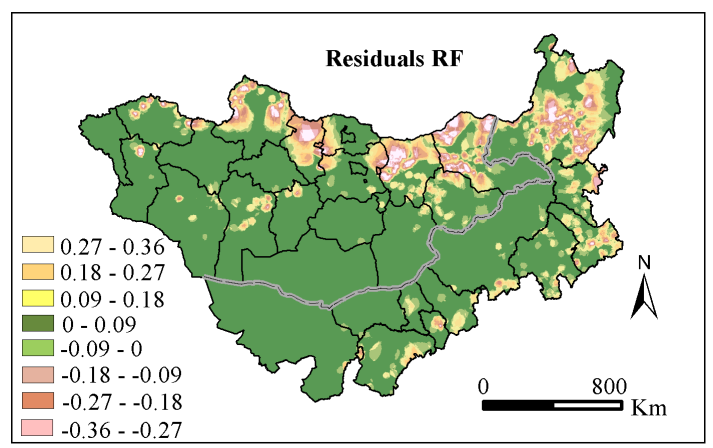

Figure 5. Spatial distribution of residual in RF models.

\section{Discussion}

When Ripley's K function is used to calculate the fire risk period distribution pattern on the Mongolian Plateau and the scale is less than $1150 \mathrm{~km}$, the wildfires are clustered. This distance scale is less than 1/2 the length of the Mongolian Plateau; that is, it does not exceed the boundary effects in the study area and meets the requirements of Ripley's K function. Therefore, the result of the wildfire aggregation distribution pattern in the study area is credible. In northeast Inner Mongolia, the fire risk periods of wildfires are distributed in a cluster pattern; among them, the aggregated distribution patterns in January, December, and July are not significant, and those for the rest of the months are significant [35]. The spatial distribution is similar to the results of our study.

The RF model was used to analyse the driving factors of fire occurrence, and the results showed that the contribution rates of the FVC, LA, elevation, pre, wet, and tmx were the largest, while the influence of the aspect was the smallest. The results of this study showed that the FVC is the material basis for the occurrence of wildfires. The occurrence and development of wildfires is closely related to the characteristics, quantity, and spatiotemporal distribution of the FVC. The FVC changes with different seasons and within different time periods of the same season [26]. Meteorological factors mainly affect the occurrence of wildfire on a large scale [5,31], e.g., high temperatures and sunshine duration are variables that either alone or together can contribute to increased potential evaporation from fuels and decreased moisture of wildfire fuel, leading to an increased possibility of wildfire occurrence [34]. High precipitation and relative humidity contribute to fuel moisture, which in 
turn decreases the probability of wildfires [36]. Topographic factors have an indirect impact on the occurrence and spread of wildfires by affecting microclimates in local areas. Studies have shown that the topography has a certain impact on the occurrence of wildfires, and wildfires occur more frequently especially in arid sunny slopes, on ridges and in low altitude areas [37]. In this paper, the elevation has a greater impact than do the slope or aspect.

In addition to the above natural factors, human factors and differences between the two administrative regions also play important roles. In recent decades, the lifestyle of the herdsmen in Inner Mongolia has gradually changed from nomadism to settlement. The number of live stock has been recklessly increased to pursue economic benefits, which has caused the vegetation to exceed its threshold carrying capacity. Thus, the land degradation is very serious [38]. In Mongolia, herdsman still maintain a nomadic life. Continuous migration and recycling of the ecosystem allow for a sufficient recovery period, which mitigates degradation, and the inhibitory effect on fire is weaker [39]. Moreover, human activity and landscape destruction in areas with higher populations also reduce the area subjected to fire. In Inner Mongolia, strict control measures and efforts to fight fires in the region have been strongly suppressed. In addition, human and financial constraints have a negative effect on fire mitigation and fire-fighting, and management measures in Mongolia are relatively underdeveloped [40]. Herdsmen take a natural approach towards wildfire. Therefore, the occurrence of wildfire is close to the natural level observed in the ecosystem. The differences in wildfire characteristics between Inner Mongolia and Mongolia indicate that in Inner Mongolia human activities have become an important factor affecting wildfire behaviours.

The likelihood distribution of wildfires on the Mongolian Plateau shows that wildfires are mainly concentrated in the border areas of Inner Mongolia and Mongolia, the northern part of Mongolia, and the northeastern and central parts of Inner Mongolia. In the northern and eastern areas of the Mongolian Plateau, due to the good meteorological and vegetation conditions, the species regeneration and biomass increase rapidly after burning [41]. The fuels reaccumulate in a short time and cause wildfire. Therefore, the northern and eastern areas have the highest probability of wildfires. Because of the serious desertification and less litter fuel, it is difficult for wildfires to occur and spread in desert areas, and the probability of fire occurrence is the lowest in these areas [42-44]. On the other hand, the contribution rate of human factors in some areas with a high probability of wildfire occurrence is also higher. For example, in the eastern part of Inner Mongolia, there is more cultivated land; in the spring and autumn, farmers burn straw infrequently to increase the probability of wildfires [29].

This study continuation the theory and techniques of wildfire event research and advance the research of risk and risk chains by enabling decision-makers to determine the probability of wildfire in the next year according to the driving factors or fire risk zone and to plan for disaster prevention. However, the Mongolian Plateau is composed a variety of land use types, which are influenced by various factors (in addition to the driving factors considered in this paper), and lead to uncertain wildfire driving factors. Moreover, because part of the data in the study area cannot be obtained, the driving factors cannot be comprehensively analysed and the satellite data cannot be verified. Therefore, to further explore the spatial distribution mechanism of wildfire occurrence, we need to further consider the impacts of specific factors on wildfire occurrence. For example, the moisture content of combustibles is an important factor to determine whether combustibles can ignite and burn. The flammability of combustibles increases with the decrease in the moisture content. The moisture content of grassland combustibles is constantly changing under the influence of rainfall, snow and air humidity. Among the human activity factors, the population size, age structure, industrial structure, and farming methods all influence fire occurrence. There is a certain relationship between these driving factors and fire occurrence, which makes fire occurrence more complex. Selecting appropriate research scales in later studies and studying the specific driving factors affecting fire occurrence is one of the most important methods by which to reveal the law of fire occurrence. The relationship between the parameters of wildfires and their influencing factors varies with the regional scale chosen. Therefore, future research should focus on how to establish a clear relationship between wildfires and their 
influencing factors. This approach would lay the foundation for further predicting the occurrence of wildfires under future climate change.

\section{Conclusions}

The distribution of wildfires in the fire risk period is an aggregated distribution within $1150 \mathrm{~km}$. The aggregation intensity in May is the largest, followed by those in June, September and October, and the smallest is in April. The contribution rates of various influencing factors and the probability of fire occurrence on the Mongolian Plateau were analysed using an RF model, and the results indicated that the FVC, LA, elevation, pre, wet and tmx had the largest contribution rates, while aspect had the lowest contribution rate. The areas with the highest wildfire probabilities were mainly concentrated in the northern, eastern and southern parts of the Mongolian Plateau and in the border area between Inner Mongolia and Mongolia, but wildfires do not occur or occur less frequently in the hinterland area. The wildfire risk zones on the Mongolian mostly occur in the east and north and seldom occur in the south and west. In Inner Mongolia, the wildfire risk zone shows a striped pattern from the northeast to southwest. The RF model fits all the samples very well. The positive and negative residuals of the RF model were smaller across the Mongolian Plateau. Maps depicting the probability of wildfire occurrence identify fire prone zones on the Mongolian Plateau, where more fire prevention resources such as fire towers and inspection stations should be allocated.

Author Contributions: All authors contributed meaningfully to this study. Conceptualization, H.Z.; Methodology, W.R.; Software, G.D., H.L., H.Y.; Validation, X.G.; Formal Analysis, W.R.; Data Curation, J.Z.; Writing-Original Draft Preparation, W.R.; Writing一Review \& Editing, H.Z.; Supervision, J.Z.

Funding: This work was supported by the National Natural Science Foundation of China (Grant number 41871330, 41571489, 41461102, 41771450, 41601438), Inner Mongolia Autonomous Region Science and Technology Program Funding Project (201502113), the Fundamental Research Funds for the Central Universities (Grant No. 2412019BJ001) and the Foundation of the Education Department of Jilin Province in the 13th Five-Year project (Grant No. JJKH20190282KJ).

Conflicts of Interest: The authors declare no conflict of interest.

\section{References}

1. Stephens, S.L.; Agee, J.K.; Fulé, P.Z.; North, M.P.; Romme, W.H.; Swetnam, T.W.; Turner, M.G. Managing Forests and Fire in Changing Climates. Science 2013, 342, 41-42. [CrossRef]

2. Sun, R.; Krueger, S.K.; Jenkins, M.A.; Zulauf, M.A.; Charney, J.J. The importance of fire-atmosphere coupling and boundary-layer turbulence to wildfire spread. Int. J. Wildland Fire 2009, 18, 50. [CrossRef]

3. Hu, Y.; Wang, S.; Song, X.; Wang, J. Precipitation changes in the mid-latitudes of the Chinese mainland during 1960-2014. J. Arid Land 2017, 9, 924-937. [CrossRef]

4. Yu, Y.; Pi, Y.; Yu, X.; Ta, Z.; Sun, L.; Disse, M.; Zeng, F.; Li, Y.; Chen, X.; Yu, R. Climate change, water resources and sustainable development in the arid and semi-arid lands of Central Asia in the past 30 years. J. Arid Land 2019, 11, 1-14. [CrossRef]

5. Liu, M.; Zhao, J.; Guo, X.; Zhang, Z.; Tan, G.; Yang, J. Study on Climate and Grassland Fire in HulunBuir, Inner Mongolia Autonomous Region, China. Sensors 2017, 17, 616. [CrossRef] [PubMed]

6. Kontoes, C.; Keramitsoglou, I.; Papoutsis, I.; Sifakis, N.; Xofis, P. National Scale Operational Mapping of Burnt Areas as a Tool for the Better Understanding of Contemporary Wildfire Patterns and Regimes. Sensors 2013, 13, 11146-11166. [CrossRef]

7. Ying, H.; Shan, Y.; Zhang, H.; Yuan, T.; Rihan, W.; Deng, G. The Effect of Snow Depth on Spring Wildfires on the Hulunbuir from 2001-2018 Based on MODIS. Remote Sens. 2019, 11, 321. [CrossRef]

8. Cao, X.; Cui, X.; Yue, M.; Chen, J.; Tanikawa, H.; Ye, Y. Evaluation of wildfire propagation susceptibility in grasslands using burned areas and multivariate logistic regression. Int. J. Remote Sens. 2013, 34, 6679-6700. [CrossRef]

9. Yue, J.; Feng, H.; Yang, G.; Li, Z. A Comparison of Regression Techniques for Estimation of Above-Ground Winter Wheat Biomass Using Near-Surface Spectroscopy. Remote Sens. 2018, 10, 66. [CrossRef] 
10. Guo, F.; Wang, G.; Su, Z.; Liang, H.; Wang, W.; Lin, F.; Liu, A. What drives forest fire in Fujian, China? Evidence from logistic regression and Random Forests. Int. J. Wildland Fire 2016, 25, 505. [CrossRef]

11. Pierce, A.D.; Farris, C.A.; Taylor, A.H. Use of random forests for modeling and mapping forest canopy fuels for fire behavior analysis in Lassen Volcanic National Park, California, USA. For. Ecol. Manag. 2012, 279, 77-89. [CrossRef]

12. Liu, Y.; Li, F.; Yu, X.; Yuan, J.; Zhou, D. Assessing the Credit Risk of Corporate Bonds Based on Factor Analysis and Logistic Regress Analysis Techniques: Evidence from New Energy Enterprises in China. Sustainability 2018, 10, 1457. [CrossRef]

13. Cutler, D.R.; Edwards, T.C.; Beard, K.H.; Cutler, A.; Hess, K.T.; Gibson, J.; Lawler, J.J. RANDOM FORESTS FOR CLASSIFICATION IN ECOLOGY. Ecology 2007, 88, 2783-2792. [CrossRef] [PubMed]

14. Kim, O.; Kang, D.-J. Fire detection system using random forest classification for image sequences of complex background. Opt. Eng. 2013, 52, 067202. [CrossRef]

15. Na, L.; Zhang, J.; Bao, Y.; Bao, Y.; Na, R.; Tong, S.; Si, A. Himawari-8 Satellite Based Dynamic Monitoring of Grassland Fire in China-Mongolia Border Regions. Sensors 2018, 18, 276. [CrossRef] [PubMed]

16. Bao, G.; Qin, Z.; Bao, Y.; Zhou, Y.; Li, W.; Sanjjav, A. NDVI-Based Long-Term Vegetation Dynamics and Its Response to Climatic Change in the Mongolian Plateau. Remote Sens. 2014, 6, 8337-8358. [CrossRef]

17. Alonso-Canas, I.; Chuvieco, E. Global burned area mapping from ENVISAT-MERIS and MODIS active fire data. Remote Sens. Environ. 2015, 163, 140-152. [CrossRef]

18. Hantson, S.; Padilla, M.; Corti, D.; Chuvieco, E. Strengths and weaknesses of MODIS hotspots to characterize global fire occurrence. Remote Sens. Environ. 2013, 131, 152-159. [CrossRef]

19. Nogueira, J.; Ruffault, J.; Chuvieco, E.; Mouillot, F. Can We Go Beyond Burned Area in the Assessment of Global Remote Sensing Products with Fire Patch Metrics? Remote Sens. 2016, 9, 7. [CrossRef]

20. Dong, Y.; Yan, H.; Wang, N.; Huang, M.; Hu, Y. Automatic Identification of Shrub-Encroached Grassland in the Mongolian Plateau Based on UAS Remote Sensing. Remote Sens. 2019, 11, 1623. [CrossRef]

21. Giglio, L.; Schroeder, W.; Justice, C.O. The collection 6 MODIS active fire detection algorithm and fire products. Remote Sens. Environ. 2016, 178, 31-41. [CrossRef] [PubMed]

22. Le Hégarat-Mascle, S.; Ottlé, C.; Guérin, C. Land cover change detection at coarse spatial scales based on iterative estimation and previous state information. Remote Sens. Environ. 2005, 95, 464-479. [CrossRef]

23. Harris, I.; Jones, P.D.; Osborn, T.J.; Lister, D.H. Updated high-resolution grids of monthly climatic observations-the CRU TS3.10 Dataset: UPDATED HIGH-RESOLUTION GRIDS OF MONTHLY CLIMATIC OBSERVATIONS. Int. J. Climatol. 2014, 34, 623-642. [CrossRef]

24. Wen, J.; Lai, X.; Shi, X.; Pan, X. Numerical simulations of fractional vegetation coverage influences on the convective environment over the source region of the Yellow River. Meteorol. Atmospheric Phys. 2013, 120, 1-10. [CrossRef]

25. Haase, P. Spatial pattern analysis in ecology based on Ripley's K-function: Introduction and methods of edge correction. J. Veg. Sci. 1995, 6, 575-582. [CrossRef]

26. Li, Y.; Zhao, J.; Guo, X.; Zhang, Z.; Tan, G.; Yang, J. The Influence of Land Use on the Grassland Fire Occurrence in the Northeastern Inner Mongolia Autonomous Region, China. Sensors 2017, 17, 437. [CrossRef]

27. Wang, Y.; Xia, S.T.; Tang, Q.; Wu, J.; Zhu, X. A Novel Consistent Random Forest Framework: Bernoulli Random Forests. IEEE Trans. Neural Netw. Learn. Syst. 2018, 29, 3510-3523. [CrossRef]

28. Berhane, T.; Lane, C.; Wu, Q.; Autrey, B.; Anenkhonov, O.; Chepinoga, V.; Liu, H. Decision-Tree, Rule-Based, and Random Forest Classification of High-Resolution Multispectral Imagery for Wetland Mapping and Inventory. Remote Sens. 2018, 10, 580. [CrossRef]

29. Guo, F.; Innes, J.L.; Wang, G.; Ma, X.; Sun, L.; Hu, H.; Su, Z. Historic distribution and driving factors of human-caused fires in the Chinese boreal forest between 1972 and 2005. J. Plant Ecol. 2015, 8, 480-490. [CrossRef]

30. Cho, H.; Matthews, G.J.; Harel, O. Confidence Intervals for the Area Under the Receiver Operating Characteristic Curve in the Presence of Ignorable Missing Data: Confidence Intervals for AUC with Missing Data. Int. Stat. Rev. 2018, 87, 152-177. [CrossRef]

31. Guo, F.; Su, Z.; Wang, G.; Sun, L.; Lin, F.; Liu, A. Wildfire ignition in the forests of southeast China: Identifying drivers and spatial distribution to predict wildfire likelihood. Appl. Geogr. 2016, 66, 12-21. [CrossRef]

32. Zhang, Z.; Feng, Z.; Zhang, H.; Zhao, J.; Yu, S.; Du, W. Spatial distribution of grassland fires at the regional scale based on the MODIS active fire products. Int. J. Wildland Fire 2017, 26, 209. [CrossRef] 
33. Mu, X.; Song, W.; Gao, Z.; McVicar, T.R.; Donohue, R.J.; Yan, G. Fractional vegetation cover estimation by using multi-angle vegetation index. Remote Sens. Environ. 2018, 216, 44-56. [CrossRef]

34. Cramer, W.; Bondeau, A.; Woodward, F.I.; Prentice, I.C.; Betts, R.A.; Brovkin, V.; Cox, P.M.; Fisher, V.; Foley, J.A.; Friend, A.D.; et al. Global response of terrestrial ecosystem structure and function to $\mathrm{CO}_{2}$ and climate change: results from six dynamic global vegetation models. Glob. Change Biol. 2001, 7, 357-373. [CrossRef]

35. Vargas, R.; Collins, S.L.; Thomey, M.L.; Johnson, J.E.; Brown, R.F.; Natvig, D.O.; Friggens, M.T. Precipitation variability and fire influence the temporal dynamics of soil $\mathrm{CO} 2$ efflux in an arid grassland. Glob. Chang. Biol. 2012, 18, 1401-1411. [CrossRef]

36. Barlow, J.; Peres, C.A.; Lagan, B.O.; Haugaasen, T. Large tree mortality and the decline of forest biomass following Amazonian wildfires: Biomass decline following Amazonian fires. Ecol. Lett. 2002, 6, 6-8. [CrossRef]

37. Ganteaume, A.; Long-Fournel, M. Driving factors of fire density can spatially vary at the local scale in south-eastern France. Int. J. Wildland Fire 2015, 24, 650. [CrossRef]

38. Li, Z.; Wu, W.; Liu, X.; Fath, B.D.; Sun, H.; Liu, X.; Xiao, X.; Cao, J. Land use/cover change and regional climate change in an arid grassland ecosystem of Inner Mongolia, China. Ecol. Model. 2017, 353, 86-94. [CrossRef]

39. Liu, X.; Zhang, J.; Cai, W.; Bao, Y. Estimating the insurance rates for loss of annual production of grass herbage associated with natural disasters in China. Rangel. J. 2015, 37, 139. [CrossRef]

40. Tong, S.; Lai, Q.; Zhang, J.; Bao, Y.; Lusi, A.; Ma, Q.; Li, X.; Zhang, F. Spatiotemporal drought variability on the Mongolian Plateau from 1980-2014 based on the SPEI-PM, intensity analysis and Hurst exponent. Sci. Total Environ. 2018, 615, 1557-1565. [CrossRef]

41. Gao, Q.; Schwartz, M.W.; Zhu, W.; Wan, Y.; Qin, X.; Ma, X.; Liu, S.; Williamson, M.A.; Peters, C.B.; Li, Y. Changes in Global Grassland Productivity during 1982 to 2011 Attributable to Climatic Factors. Remote Sens. 2016, 8, 384. [CrossRef]

42. Tong, S.; Zhang, J.; Bao, Y.; Lai, Q.; Lian, X.; Li, N.; Bao, Y. Analyzing vegetation dynamic trend on the Mongolian Plateau based on the Hurst exponent and influencing factors from 1982-2013. J. Geogr. Sci. 2018, 28, 595-610. [CrossRef]

43. Bao, G.; Liu, Y.; Liu, N.; Linderholm, H.W. Drought variability in eastern Mongolian Plateau and its linkages to the large-scale climate forcing. Clim. Dyn. 2015, 44, 717-733. [CrossRef]

44. Liu, H.; Cui, H.; Pott, R.; Speier, M. Vegetation of the woodland-steppe transition at the southeastern edge of the Inner Mongolian Plateau. J. Veg. Sci. 2000, 11, 525-532. [CrossRef] 